\title{
A Critical Insight into Needs Assessment Technique and the Way Social Needs are Actually Assessed
}

\author{
Hamidou Issaka Diori \\ The Graduate School of Public Administration (GSPA), National Institute of Development \\ Administration (NIDA), Bangkok 10240, Thailand \\ * Corresponding author email: idioha@yahoo.fr
}

Received: 27 November 2020 / Revised: 29 December 2020 / Accepted: 31 December 2020 / Published: 02 January 2021

\begin{abstract}
Needs assessment is regarded as a powerful tool for addressing the needs for a program, and for various other purposes including strategic planning for resource allocation, priority setting, and improving the course of an ongoing program. As such, it is portrayed as an ideal and necessary step in policymaking. On the other hand, however, there are some growing concerns about the actual needs assessment practice which is believed by many to be prejudicing the performance of countless policies and programs. Hence, looking into this dichotomy of views and the way social needs are actually assessed are of particular interest. The present contribution seeks to delve deep into the technique of needs assessment and to give an insight on what ought to be done in the field and what is being done in fact. A systematic literature search was conducted to identify and analyze all available research studies that address the function of needs assessment, the problem definition in need assessment, the identification and classification of needs, the definition, description, and specification of target populations, and the description of the nature of service needs. The content of the relevant sections in each study was then read and reread with the aim of determining how social needs are assessed indeed. The result has shown that needs, their identification, and the way they are met, are in most cases determined by experts and agencies, not the needy populations. The search has also revealed the existence of significant gaps between the needs identified by professionals and those seen as important by the people who they are supposed to benefit. Finally, the result suggests that experts and agencies' definition and identification of needs or target populations only reflect their own views or choices of program activity and the reasons they brandish in seeking for funding.
\end{abstract}

Keywords: needs assessment; policy evaluation; social needs

\section{Introduction}

Rossi, Lipsey, and Henry (2019) said of a needs assessment activity to be the evaluation part that examines the social problems. Put in different words, needs assessment is the means by which an evaluator determines whether there is a need for a program and if so, what are the nature and extent of that need and the related implications for the program services that are put in place to address the need (2019). As we can see, assessing population needs is critical for the design of a new program. It is also relevant for on-going programs, especially when it is unsure those programs are meeting the needs for which they have been tailored.

Until recently, the academic account of the practice of needs assessment was the only, or say, main narration of the way social needs are assessed, or to be assessed. Judged too eulogistic however, and too detrimental to effective policy and decision-making, that account of needs assessment is today challenged by a more realistic view of the way social needs are being assessed and determined in real life situation. The objective of the present review is to dig deep into the technique and practice of needs assessment and to shed light on what is being done in fact in this particular evaluation activity. In so doing, it seeks to contribute to the efforts of exposing some common practices and biases in social policy and needs evaluation. To facilitate the analysis, a systematic literature search was conducted to echo and examine the standpoint of other 
scholars about the issue. The findings have revealed a substantial gap between the technique that is being taught and extolled and the one that experts and agencies utilize in practice. The findings have also revealed some great discrepancies between what is considered as needs by agencies and so-called experts (normative needs) and the actual needs as reported by actual populations (felt needs). Gough (2004) and Alkire (2005) for instance, noted that needs and the way they are defined or met, are very often determined by experts, not the people who they are supposed to benefit. And as evidence may alter over time and experts disagreeing over definitions, differences may subsist in these "normatively" defined needs. Moreover, several studies in health care have revealed significant differences in the needs identified by professionals as opposed to those seen as important by patients, Bouthillette (2007, as cited in Beran, 2015; Ní Shé, 2020). The remainder of this review is structured as followed: section 2 discusses the function of needs assessment and supports the analysis with illustrative examples of an inadequate diagnosis of social needs. Section 3 critically reviews some issues pertaining to the biases in problem definition in assessing social needs. Section 4 analyzes the biased needs identification and classification with some illustrations. Section 5 examines the biased definition and identification of target population. Section 6 deals with the bias in target population description and specification. Section 7 evaluates the problems with the description of the nature of service needs. Finally, section 8 culminates the study with a reminder of the findings and some recommendations as for how to tighten the gap between actual population needs and those that are defined and agreed upon by agencies and evaluators. It also illustrates the limitations of the study.

\section{Function of needs assessment}

Needs assessments as evaluation segments are not always conducted with reference to a specific social program or program proposal (Rossi et al., 2019). They are also utilized as planning tools or decision aids for policy makers who may want to prioritize among some competing needs (2019). In general, assessing the needs can help keep unnecessary programs from being developed and executed. And when such programs are already designed and put to practice, needs assessment could be used to reorient their attention to changes in the respective social condition (Rossi et al., 2019).

Viewed in the perspective of Chen's comprehensive evaluation typology (which comprises all stages of a policy cycle from planning to implementation to outcome), needs assessment is a constructive tool (or type of evaluation) providing pertinent information and assistance intended to help stakeholders develop plan and program rationale (Chen, 2015). Lastly, a thorough needs assessment has the potential to alert policy makers and advocates to a broader set of needs, concerns, or responses that an existing program might have failed to identify.

In the light of all that precedes, we can easily say that to get to alleviate a social problem, an appropriate needs identification is mandatory, and that, failure to do so might be detrimental to a program or policy outcome. In a study of ethnic minority needs in cancer care for instance, Moadel, Morgan, and Dutcher (2007) have attempted to examine the unmet and unwanted needs of the program participants. Reviewing the needs of these patients which the program evaluators have identified as emotional, physical, daily life, support, financial issues, information, and spiritual, Moadel et al.(2007) believed that these needs may not be applicable to the specific sub-population they have studied.

This short illustration of an inadequate diagnosis of social needs, reveals one of the key issues people face in tailoring a response to patients' needs in health care. That problem resides in the fact that health care workers are more focused on treating the specific disease rather than addressing the patient as a whole (Eldridge et al. 2011; Currid, 2012; Hill et al., 2015). The same issue was equally highlighted in a variety of studies where the specific needs of the elderly were not exactly taken into consideration, Deck, Richter, and Huppe (2009, as cited in Beran, 2015). In a similar study, Currid (2012) went further to reveal that, notwithstanding the promotion of the biopsychosocial model into nursing practice, there were clear indications that nurses were not meeting their patients' holistic needs, causing unneedful poor access to relevant services, suffering, and even death, in some cases. 


\section{Bias in Problem definition}

Social problems are not objective phenomena said Rossi, Lipsey and Henry (2019). They are social constructs implying assertions that certain conditions constitute problems that require public attention and appropriate interventions (Rossi et al., 2019). That may explain why the definition of a social problem and the specification of intervention goals occur sometimes in a way which does not follow spontaneously from the essential characteristics of the situation. Problem definition is primarily informative and ought to help the evaluator to determine what the major political actors think the problem is (2019). But oftentimes, evaluators side with the agencies or clients for whom they are working, leaving the door open for biases and deliberate misinterpretations of reality. Pressman and Wildavsky (1973) have shown how lack of proper problem definition and service identification have led to the failure of the Urban Aid policy in Oakland. The project which bears the name of the city was marred by vested interests and this can be seen from the choice of the city of Oakland as aid recipient and that of the EDA as donor instead of the New department of Housing and Urban Development. The choice of Oakland even came as a surprise for many observers because the first aid packages should have gone to New York, Chicago, Los Angeles, or other major cities whose poverty and racial tensions have already erupted into public demonstration or riots (1973).

Bias in social problems definition may also come from respondents. This is known as response bias. In this case, the assessor ought to be able to sort the lots of responses and use adequate tools in order to suppress eventual biased data. Brief, in defining social problems, program evaluators must specify the extent of the problems. This consists in the words of Rossi et al. to answer the questions, when, where, and above all, how big is the problem, because the planning and funding of a social program is determined by the size, distribution, and density of the problematic conditions (2019). Very often unfortunately, problems are not defined in such a manner in all need assessment endeavors.

VeneKlasen, Miller, Budlender, and Clark (2007) posited that many advocacy strategies have difficulty in achieving their goals because the problem they seek to address is either not clearly defined; or not perceived as a priority problem by a large number of people; or not narrowed down sufficiently to a particular issue with a workable strategy. The reason we are interested in here is that of the lack of clear problem definition which could cause the occurrence of the two other reasons. But sometimes, the difficulties that advocacy strategists met simply occur because they respond more to donor trends than real needs and opportunities for change (Veneklasen et al., 2007). In other circumstances, Veneklasen et al. argued that: "NGO staff 'cook up' a project or strategy based on well-intentioned assumptions about the problems that 'poor women' or 'rural farmers' face. Meanwhile poor women and farmers may have different priorities and desired solutions" (2007, p.125). Occasionally also, the way the problems are defined does not correspond to the way they are perceived by those people. Thus, those enduring the conditions cannot relate to the proposed solution (2007).

\section{Biased need identification and classification}

Another source of bias in needs assessment resides in the classification or say, typology of needs. Royse, Thyer and Padgett (2016) provided four ways in which needs can be viewed. This typology, also referred to as Bradshaw conception of four needs, is another source of concern in needs assessment. It classifies needs into four main categories namely: Normative, felt, expressed, and comparative. Out of these need classes, only the normative ones are commonly taken into consideration because they are defined by experts who sometimes know less about people's condition for relying mainly on dubious secondary data or inaccurate third-party information.

The felt needs, the second category, are the perception of need as reported by actual clients. Here clients collect data based on surveys which may not be accurate or exhaustive since they (clients) may refrain from telling investigators directly what their most perceived needs are.

The third category of needs is called 'expressed needs'. These are demands for services from a specific program. Usually, few of these demands are accepted because experts view them as 'want' or 'desires', and 
whenever they accept them, they ought to be in the form of comparative needs (the fourth category of the Bradshaw conception of needs). Comparative needs are inferred measures of needs determined by examining the characteristics of those demanding or receiving services and then locating those characteristics in the population (Royse et al., 2016). Bradshaw conception of four needs could have been a clean way of needs assessment if and only if, actual populations' views are taken into consideration not only those of experts and clients. The failure to accurately identify, classify and thoroughly address social needs, often leads to a program or agency being either ineffective or unacceptable.

Looking into a need assessment program of cancer survivors in Connecticut, Tish Knobf et al. (2012) have found several knowledge gaps concerning the needs of cancer survivors and their utilization of supportive services. To get to better understand the specific needs of cancers survivors, the Connecticut Cancer Partnership's (CCP) Survivorship Committee called for a need assessment of its population. The CCP is the voluntary comprehensive cancer control coalition in Connecticut, recognized by the US Centers for Disease Control and Prevention, to work in partnership with the state Department of Public Health in supporting a coordinated approach to comprehensive cancer control (2012). The committee has created many support services for cancer survivors in Connecticut, however, due to biased needs identification and classification, they are often unknown or underutilized by the populations for whom they are designed (Tish Knobf et al., 2012).

\section{Biased definition and identification of target population}

The target population of a social program also referred to as target audience or population of intervention, is usually made of individuals, geographically or politically related areas (such as communities); or physical units (Rossi et al., 2019). It is crucial at the beginning of a needs assessment to clearly define the units that account for that population since a policy or program cannot be effective unless those implementing it are able to do two things: first to know what the target population is and second, to direct the program services toward these individuals (2019). While doing all this, they must also be able to screen about groups or people who are not part of the target population. However, due to scarcity of funding or their limitation, due to problems of definition, or other biased considerations, problems always subsist when it comes to either define or identify target populations.

Regber et al. (2013) conducted a study to assess possible selection bias of participants in the IDEFICS (Identification and prevention of dietary-and lifestyle-induced health effects in children and infants) Sweden 2006 project which was meant to evaluate children's health condition with particular attention on obesity and to design a health-promoting community intervention scheme. It was found that households with low education and income, single parenthood, and foreign background, were underrepresented in that study. Worse, neither the survey that was performed, nor the IDEFICS study as a whole, gave clear indications as to whether the target audience were typical representation of the general population in terms of social and economic condition. Regber et al. (2013) hinted that selection biases might have occurred to some extent, and probably made their way into the survey findings and conclusions.

\section{Bias in target population description and specification}

A program's approval and likelihood of success depend a great deal on the nature of the target population the program is supposed to serve. For that reason, it is important to carefully identify and describe the actual population with actual needs. To be able to do so, we need to frankly review and discuss the utility and usage of the present days target population typologies. Concepts and technical words such as population at risks, population in needs, population at demands .... may sound nice in the ear of the funders and stakeholders of a social program but in truth, they are rarely of great utility as they do not always help determine the actual population in needs.

Having in mind the difficulties that programs implementers are facing in describing and specifying the needy populations, other concepts have been laid down and wired into the assessment jargon in a bid to better describe the populations whose conditions programs are to improve. Hence, the terms of incidence, 
Hamidou Issaka Diori, Adv. J Social Sci.; Vol. 8, Issue 1, pp: 3-9, 2021

prevalence, and rate have emerged as palliative without making any difference in fact. However, to blame recurrent biases in the description and specification of target population on the solely confusion or misuse of the aforementioned concepts and technical words is piecemeal. For, biases also spring from the plurality of perspectives that policy and decision makings naturally deal with. In fact, different perspectives sometimes arise from the definition by professional, politicians, and other stakeholders. To resolve the problem of biases in target population description and specification, evaluators should take into consideration all perspectives including those of actual populations and come up with workable target population typologies or classification tools.

In a study conducted on needs assessment in a youth development program and the types of justice interventions to be used for the youth in the US, St. John, Murphy and Liberman (2020) has shown how biased and improper description and specification of target populations are more likely to misclassify youth of color as high-risk than their white counterparts. As a result, the lack of suitable assessments which are supposed to better predict a youth's likelihood of future offending than a justice official's professional judgment, disproportionately impacts youth of color. In sum, a proper need assessment in that context was to reduce bias in juvenile justice sanctions by providing justice officials with a consistent set of criteria to judge a youth's risk for offending. But due to biases in target population specification and precisely an inappropriate youth's risk level assessment, there is an overrepresentation and differential treatment of people of color in the criminal and juvenile justice systems in the united states.

\section{Problems with the description of the nature of service needs}

To be effective, a social program of any kind must adapt its services to the local nature of the problem and the distinctive conditions of the target population (Rossi et al., 2019). This in turn necessitates a great deal of information about the way in which the problem is felt by those in that population, their perspectives and attributions about relevant services and programs; and the barriers and difficulties they experience in seeking to access services (2019). Let's not forget that a key function of needs assessment is to yield estimates of the scope and distribution of a specific problem and the related population of intervention. When such estimates and further other relevant information are known, considerations should then be given to cultural factors or perceptions and attributions that characterize a target population in ways that interact with their receptibility in program services. But very often, agencies care less about people's perception, or cultural and moral factors especially in remoted and very depressed areas. As a result, any policy which does not take people's perception into account will fail to reach its desired outcome because it may be viewed as unacceptable. For instance, to be effective, a needs assessment on poverty in rural populations ought to highlight the sensitivities of the target population to accepting handouts and the strong value they placed on self-sufficiency. Programs which do not take those norms into consideration while describing the nature of service needs may fail to alleviate the economic condition of these populations. Another pertinent dimension of the nature of service needs involves practical difficulties some members of the target population face in using social program services. These could either be a problem of accessibility (remoted service point and lack of transportation) or a problem of service availability (such as limited services hours), or a problem of awareness (members of populations failing to know where to go if they need a service). The amount of attention that is paid to overcome barriers such as these, determines the difference between a program with an effective service delivery to persons in needs and an ineffective one.

Bani (2008) pointed out that in most developing countries, healthcare services have rarely taken into consideration how local people explain illness, how they seek advice, or use traditional healing methods. The emphasis has been on hospitals and curative care rather than trying to address local health needs comprehensively. To tackle the issue of biased and ineffective needs identification and classification, and mostly to develop appropriate public health research strategies that address community problems, active collaboration between local communities and health needs evaluators is critical, said Bani (2008) 
Nowadays, governments throughout the world seem to understand that involving patients leads to more accessible and acceptable services and the improvement of health and quality of life of patients. That helps save money, time and personal efforts too.

\section{Conclusion}

Given the function and reasons for a needs assessment endeavor, it ought to be able to capture the full range and scope of the needs of all people in need and this should encompass the whole of normative, felt, expressed and comparative needs. Experts and agencies' definition and identification of needs or target population may only reflect their own view or choice of program activity and the reasons they brandish in seeking for the program funding. To help tighten the gap between actual population needs and those that are defined and agreed upon by agencies and evaluators, needy populations ought to be listen to and included in the process of needs assessment and in general, the planning and development of social programs. Moreover, program assessors need to have full autonomy and moral probity to better perform their tasks. In order to improve or depart from the way needs are being assessed, we need to rethink the concept of assessment and select the best possible approaches, tools, and people for the task. The present study contributes to these efforts by exposing some common biases in needs assessment before calling for further research to be conducted on the topic. It's only in so doing that we can provide the field of evaluation with plausible hands-on assessment tools that are capable to yield more efficient and effective policy and decision makings. Finally, the study may have fallen short to provide detailed and thorough recommendations as to how and what measures should be taken to avoid bias in needs assessment, but it has at least the merit to expose what most are seeing, yet incapable to openly discuss. Needs assessment in its actual form and handling is detrimental to effective decision-making and policy implementation.

\section{Competing Interests}

The author declares that no conflict of interest exists in this publication.

\section{How to Cite this Article:}

Diori, H. I. (2021). A Critical Insight into Needs Assessment Technique and the Way Social Needs are Actually Assessed. Advanced Journal of Social Science, 8(1), 3-9. https://doi.org/10.21467/ajss.8.1.3-9

\section{References}

Alkire, S. (2005). Valuing freedoms: Sen's capability approach and poverty reduction. Oxford University Press.

Bani I. A. (2008). Health needs assessment. Journal of family \& community medicine, 15(1), 13-20.

Beran, D. (2015). Needs and Needs Assessments: A Gap in the Literature for Chronic Diseases. SAGE Open. https://doi.org/10.1177/2158244015580375

Chen, H. T. (2015). Practical Program Evaluation: Theory-Driven Evaluation and the Integrated Evaluation Perspective (2 ${ }^{\text {nd }}$ Edition). Sage Publication, Thousand Oaks, CA.

Currid, T. (2012) Meeting the psychological needs of the physically ill. Nursing Times, 108(46), 22-25. https://www.nursingtimes.net/meetingthe-psychological-needs-of-the-physically-ill/5051622.article

Eldridge, D., Dawber, N., \& Gray, R. (2011). A well-being support program for patients with severe mental illness: a service evaluation. $B M C$ Psychiatry, 11(46). DOI: 10.1186/1471-244X-11-46

Gough, I. (2004). Human well-being and social structures: Relating the universal and the local. Global Social Policy, 4, $289-311$.

Hill, H., Evans, J.M. \& Forbat, L. (2015). Nurses respond to patients' psychosocial needs by dealing, ducking, diverting and deferring: an observational study of a hospice ward. BMC Nursing 14(60). https://doi.org/10.1186/s12912-015-0112-8

Moadel, A. B., Morgan, C. \& Dutcher, J. (2007). Psychosocial needs assessment among an underserved, ethnically diverse cancer patient population. Cancer, 109(Suppl.), 446-454. doi:10.1002/cncr.22357

Ní Shé, É., O’Donnell, D., Donnelly, S., Davies, C., Fattori, F., \& Kroll, T. (2020) "What Bothers Me Most Is the Disparity between the Choices that People Have or Don't Have": A Qualitative Study on the Health Systems Responsiveness to Implementing the Assisted Decision-Making (Capacity) Act in Ireland. International Journal of Environmental Research and Public Health 17(9), p. 3294.

Pressman, J. L. \& Wildavsky, A. (1973). Implementation ( $2^{\text {nd }}$ edition). University of California Press.

Regber, S., Novak, M., Eiben, G., Lissner L., Hense, S., Sandström, T. Z. \& Ahrens, W. (2013). Assessment of selection bias in a health survey of children and families. The IDEFICS Sweden-study. BMC Public Health 13, 418. https://doi.org/10.1186/1471-2458-13418

Rossi, P. H., Lipsey, M.W. \& Henry, G. T. (2019). Evaluation: A Systematic Approach (8 $8^{\text {th }}$ Edition). Sage Publications.

Royse, D., Thyer, B. A. \& Padgett, D. K. (2016). Program Evaluation: An Introduction to an Evidence Based Approach (6 ${ }^{\text {th }}$ edition). Cengage Learning; Boston, MA 
Hamidou Issaka Diori, Adv. J Social Sci.; Vol. 8, Issue 1, pp: 3-9, 2021

St. John, V.; Murphy, K., \& Liberman, A. (2020). Recommendations for Addressing Racial Bias in Risk and Needs Assessment in the Juvenile Justice System. https://www.childtrends.org/wp-content/uploads/2020/01/Duke-Risk-Assessment-FAQ_ChildTrends_Jan2020-1.pdf

Tish Knobf, M., Ferrucci, L.M., Cartmel, B., Jones, B. A., Stevens, D., Smith, M., \& $\quad$ Salner, A. (2012). Needs assessment of cancer survivors in Connecticut. J Cancer Surviv 6, 1-10 (2012). https://doi.org/10.1007/s11764-011-0198-2

VeneKlasen, L., Miller, V., Budlender, D., \& Clark, C. (2007). A new weave of power, people, and politics: The action guide for advocacy and citizen participation. Practical Action Pub.

Publish your research article in AIJR journals-

$\checkmark \quad$ Online Submission and Tracking

$\checkmark$ Peer-Reviewed

$\checkmark$ Rapid decision

$\checkmark \quad$ Immediate Publication after acceptance

$\checkmark \quad$ Articles freely available online

$\checkmark \quad$ Retain full copyright of your article.

Submit your article at journals.aijr.in
Publish your books with AIJR publisher-

Publish with ISBN and DOI.

Publish Thesis/Dissertation as Monograph.

Publish Book Monograph.

Publish Edited Volume/ Book.

Publish Conference Proceedings

Retain full copyright of your books.

Submit your manuscript at books.aijr.org 